\title{
Discussion: Capillary absorption of concrete after mechanical loading
}

\author{
Licheng Wang \\ Associate Professor, State Key Laboratory of Coastal and Offshore \\ Engineering, Dalian University of Technology, Dalian, People's Republic of \\ China \\ Shuhong Li \\ Master, Qingdao Branch of Shanghai UDG Architecture Design \\ Corporation, Qingdao, People's Republic of China
}

\section{Jose R. Martí-Vargas}

Professor, ICITECH, Institute of Concrete Science and Technology,

Universitat Politècnica de València, Valencia, Spain

\section{Contribution by Jose R. Martí-Vargas}

Based on interest in understanding the transport properties of cracked/damaged concrete, the paper by Wang and Li (2014) presents an experimental investigation into capillary absorption of concrete after being subjected to uniaxial compressive or tensile loads. A series of water absorption experiments were conducted for the purpose of examining the extent to which load level and loading patterns influence the permeation of concrete.

The authors should be complimented for producing this detailed paper of interest to the discusser, who would like to offer some comments for the authors' consideration and response, mainly about the loading patterns, the effect of load level on cumulative water absorption and the relationship between both initial and second sorptivity and loading level.

Wang and Li (2014) state that it has been experimentally proven that microcracks in concrete induced by loading partially recover after unloading, and that the degree of recovery depends on the load level. The authors considered three load levels (70\%, $80 \%$ and $90 \%$ of the corresponding compression and tension loading capacity) and two loading patterns (sustained for $10 \mathrm{~min}$ and repeated for 25 cycles) to allow adequate crack propagation and to retain as much residual damage as possible after unloading. However, in the discusser's opinion, the applied load levels seem high for a representation of serviceability conditions, whereas the loading time intervals seem short for longterm prediction. By way of example, the Spanish code EHE-08 (MdF, 2008) establishes a limitation in concrete compressive stress of $60 \%$ of the specified concrete compressive strength to verify the state limit for cracks under compression and also at prestress transfer, whereas time intervals of 3 months (Arango et al., 2012; García-Taengua et al., 2014) and more than 1 year (Caro et al., 2013a, 2013b) are commonly used for long-term determinations, depending on the analysed phenomena.

The discusser is confused about the authors' statement that the two loading patterns (sustained and repeated) did not show any obvious difference in terms of effect on water sorptivity because of insufficient crack development during loading and recovery of microcracks after unloading. However, one may believe that the tension loading capacity for unreinforced concrete is associated with the cracking phenomenon. As the three load levels applied were lower than the corresponding tension loading capacity, one may assume that there should be no cracks in all these cases, which seems to contradict the purpose of the experimental programme and the obtained results.

Finally, the discusser would like to offer complementary analyses, which perhaps have not been noted by the authors, as follows.

- As observed in Figure 5, the cumulative water absorption values for the sustained compression case are higher than for the sustained tension case, whereas the cumulative water absorption values for the repeated compression case are lower than for the repeated tension case.

- As may be seen in Figure 6, the initial sorptivity values for the sustained compression case are higher than for the sustained tension case, whereas the initial sorptivity values for the repeated compression case are slightly lower than for the repeated tension case.

- As observed in Figure 7, the second sorptivity values for both the sustained and repeated loading cases do not show any significant difference in terms of the effect of loading type (compression and tension) and level.

\section{Authors' reply}

The authors thank the discusser for the interest in our work and for the valuable comments and suggestions that will help enhance understanding of the content of the original paper. Our responses to the points raised by the discusser are as follows.

The first question concerns the load levels for compression tests and loading patterns. As noted by the discusser, for real 
concrete structures, the compressive stress of concrete is much lower than the designed levels in the experimental study and, in some design codes - including the Chinese code for the design of concrete structures (CMC, 2010) - the limitation in concrete compressive stress is $80 \%$ of the compressive strength for prestressed concrete structures. We totally agree with the points raised by the discusser. However, the purpose of the work was not to simulate the real work conditions of concrete because the test methods used were not able to reflect the state of concrete under sustained load (i.e. the condition a concrete structure has to maintain). Therefore, the sample was loaded to a relatively higher loading level than in a real case, in order to induce as much residual damage as possible with the purpose of compensating the recovery of cracks after unloading (Hearn, 1999). This is because, as reported by Samaha and Hover (1992), when the compressive loading level was below $75 \%$, the transport properties of concrete did not significantly change with loading. In the tensile loading test conducted by Yang et al. (2006), load-induced damage was found in the form of non-connected interfacial or paste cracks for load levels up to $80-90 \%$ of the ultimate strength. All of their tests were performed on samples after unloading. In other words, the aim of the authors' work at this moment is just to investigate the influence of load-induced damage on the transport properties of concrete and to remind readers of the consideration of loading effects.

Regarding the loading patterns (sustained for $10 \mathrm{~min}$ and repeated for 25 cycles), considering the high loading level, the sustained time intervals and repeated cycles had to be controlled and restricted in order to avoid specimen failure during the loading process. In fact, to closely approach the service conditions of real structural concrete, the authors are still working on a way to conduct transport tests on concrete under sustained loading with a specifically designed apparatus. In this programme, the maximum compressive loading level is much lower than the levels in the published paper. It is hoped that the results of this study will be published in the open literature in the not too distant future.

For the case of tension loading - the second topic raised by the discusser - the reported study attempted to reflect the effect of tensile stress, which may cause microcracks, on the microstructure or porosity of concrete and then to study the influence on the transport properties of concrete. The test results indicated that tension loading increased the water sorptivity (see Figures 7(c) and 7(d)), although some of the damage was recovered. The discusser refers to macrocracks or visible cracks when the load levels applied are higher than the corresponding tension loading capacity. This is another case usually applied to reinforced concrete to investigate the effect of cracks on permeability because in the descending part (beyond the tension capacity), the distribution of tension strain or cracks is uniform.

We appreciate the complementary analyses offered by the discusser. For the test data shown in Figures 5, 6 and 7, the discussion and conclusions are true. In our initial opinion, the differences among the loading patterns are not remarkable, particularly considering the testing process; for example, the samples were saw-cut from the loaded specimen and ovendried, which may induce some uncertainty, along with the distinct concrete properties. Therefore, a new test programme is being developed to perform the coupled loading and absorption test with only one specimen used before loading and under loading in order to reduce the variability of the concrete material.

\section{REFERENCES}

Arango SE, Serna P, Martí-Vargas JR and García-Taengua E (2012) A test method to characterize flexural creep behavior of pre-cracked FRC specimens. Experimental Mechanics 52(8): 1067-1078.

Caro LA, Martí-Vargas JR and Serna P (2013a) Prestress losses evaluation in prestressed concrete prismatic specimens. Engineering Structures 48: 704-715.

Caro LA, Martí-Vargas JR and Serna P (2013b) Time-dependent evolution of strand transfer length in pretensioned prestressed concrete members. Mechanics of Time-Dependent Materials 17(4): 501-527.

CMC (Construction Ministry of China) (2010) GB 50010-2010: Code for design of concrete structures. Construction Ministry of China, Beijing, China (in Chinese).

García-Taengua E, Arango S, Martí-Vargas JR and Serna P (2014) Flexural creep of steel fiber reinforced concrete in the cracked state. Construction and Building Materials 65: 321-329.

Hearn N (1999) Effect of shrinkage and load-induced cracking on water permeability of concrete. ACI Materials Journal 96(2): 134-241.

MdF (Ministerio de Fomento) (2008) EHE-08: Instrucción de Hormigón Estructural. Ministerio de Fomento, Madrid, Spain.

Samaha HR and Hover KC (1992) Influence of microcracking on the mass transport properties of concrete. ACI Materials Journal 89(4): 416-424.

Wang L and Li S (2014) Capillary absorption of concrete after mechanical loading. Magazine of Concrete Research 66(8): 420-431, http://dx.doi.org/10.1680/macr.13.00331.

Yang ZF, Weiss WJ and Olek J (2006) Water transport in concrete damaged by tensile loading and freeze-thaw cycling. Journal of Materials in Civil Engineering 18(3):424-433. 